\title{
Slope stability analysis using numerical modelling
}

\author{
Ali Fawaz ${ }^{1, *}$, Elias Farah², Fadi Hagechehade ${ }^{1}$ \\ ${ }^{1}$ Lebanese University, Institute of Technology (Saida) \& Doctoral School of Sciences and Technologies, Modelling Centre, PRASE \\ Beirut, Lebanon \\ ${ }^{2}$ Lebanese University, Doctoral School of Sciences and Technologies, Modelling Centre, PRASE, Beirut, Lebanon
}

\section{Email address:}

alifawaz2014@gmail.com (A. Fawaz), elias_farah@live.com (E. Farah), fadihagechehade@hotmail.com (F. Hagechehade)

\section{To cite this article:}

Ali Fawaz, Elias Farah, Fadi Hagechehade. Slope Stability Analysis Using Numerical Modelling. American Journal of Civil Engineering. Vol. 2, No. 3, 2014, pp. 60-67. doi: 10.11648/j.ajce.20140203.11

\begin{abstract}
This paper aims to analyze slope stability based on the numerical simulation using Plaxis software. The mechanical parameters of soil layers constituting the slope are evaluated from laboratory results and numerical simulations of in-situ pressuremeter tests. The study of the slope consists to determine the failure surface and the corresponding safety factor. This coefficient is calculated taking into consideration the influence of factors that contribute slope instability and following the use of several methods of reinforcement to strengthen the slope.
\end{abstract}

Keywords: Soil, Numerical Simulation, Slope Stability, Safety Factor, Failure Surface

\section{Introduction}

Natural or landscaped slopes may lose their stability by a detachment and sliding of a soil volume along a failure surface, as a result of exceeding its shear strength. This collapse may be developed due to excavation activities and rainfall infiltrating. The slope stability analysis consists determining the soil mechanical properties, the shape and the position of the possible failure surface.

Since Fellenius [1] and Bishop [2], several authors have proposed calculation methods for slope stability based on the limit equilibrium ([3], [4], [5]). This procedure coupled with the advanced optimization techniques is adequate for regular slope stability problems [6]. The development of finite elements methods led to an effective approach for assessing the safety factor of soil slopes within its strength reduction ([7], [8], [9]).

In order to prevent the sliding, different techniques have been evolved to ensure the slope stability. Stabilizing piles have been used to secure or recover slopes that have already collapsed ([10], [11], [12]). The soil shear strength could be improved using steel nails ([13], [14], [15], [16]). The groundwater level could be lowered within drainage trenches that increase the slope stability especially during rainfall ([17], [18]).

In this study, we present a slope stability analysis using a numerical modeling. The confrontations methods mentioned above will be considered and modeled. The soil mechanical parameters of the slope layers are determined from laboratory tests on the one hand and from in-situ pressuremeter tests and numerical simulation on the other hand. Once these characteristics have been extracted, we proceed to examine the stability of an existing slope in Lebanon, which has collapsed due to excavation during the rainfall season. The calculation of slope stability is established taking into account the factors affecting slope instability and the disposition of resistance elements in order to stabilize the slope.

\section{Methodology}

This method involves drilling boreholes in different types of soil and executing in-situ pressuremeter tests at different depths. Soil samples are also taken from these boreholes to be tested in the laboratory. The experimental pressuremeter tests are numerically simulated using Plaxis software. Once the soil parameters have been determined, the slope is modeled with Plaxis, we start from the initial state of the slope before any excavation and analyze the safety factor and the surface of failure corresponding to this state. An excavation performed during the construction of a highway will be also modeled and we will focus on the parameters which have probably caused the landslide.

\section{Experimental Analysis}

Two boreholes are drilled to the depths of 53 and $54 \mathrm{~m}$ respectively inside the slipped part of the slope near Dahr 
ElBaidar - Lebanon. The borehole $\mathrm{N}^{\circ} 1$ shows the existence of two main layers: a mix of clay, gravel and cobbles of limestone from the surface to $10 \mathrm{~m}$ depth over a gravelly clayey marl layer from 10 to $53 \mathrm{~m}$. The borehole $\mathrm{N}^{\circ} 2$ shows these two same main layers but intercalated by a layer of sand between 16 and $17 \mathrm{~m}$, and another gravelly sand layer between the depths of 51 and $52.5 \mathrm{~m}$.

Two series of pressuremeter tests were performed in this site at $2 \mathrm{~m}$ intervals from the depth of $2 \mathrm{~m}$ to $34 \mathrm{~m}$ for the first borehole and to $48 \mathrm{~m}$ for the second.

The results of the pressuremeter test in the first borehole indicate that the pressuremeter modulus varies from 1.2 to $35 \mathrm{MPa}$ and the limit pressure from 300 to $2600 \mathrm{kPa}$.

For the second borehole, the values of the pressuremeter modulus are between 3.7 and $500 \mathrm{MPa}$ and the limit pressure varies from 380 to more than $4930 \mathrm{kPa}$.

Fig. 1 and 2 show the evolution of the pressuremeter curves with depth for boreholes 1 and 2 respectively.

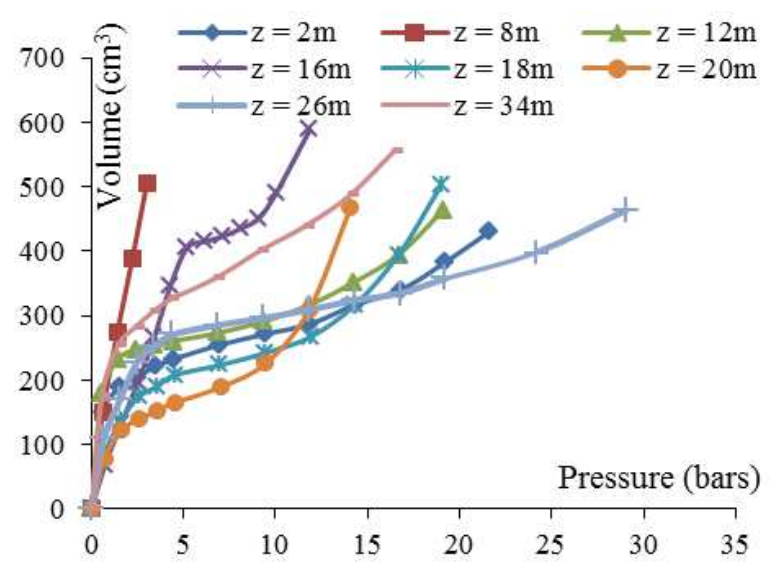

Figure 1. Evolution of pressuremeter curves with depth for borehole 1.

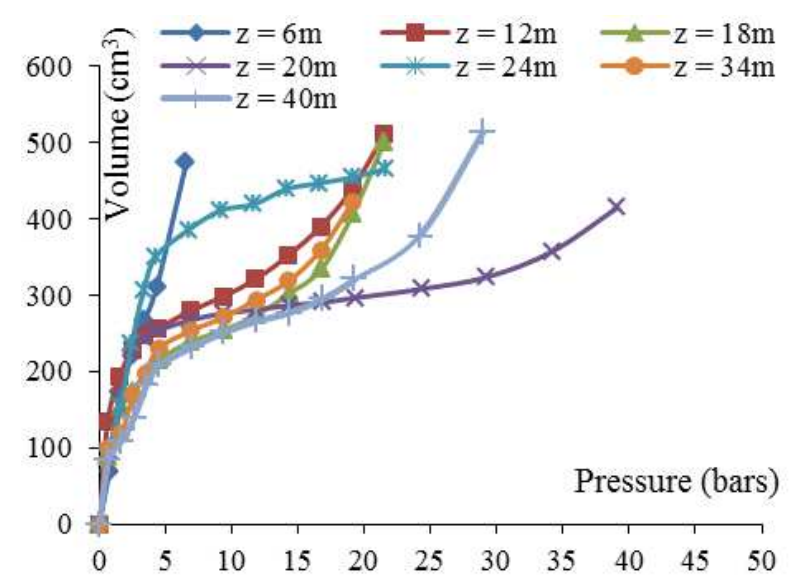

Figure 2. Evolution of pressuremeter curves with depth for borehole 2.

\section{Estimation of Mechanical Soil Parameters}

Experimental pressuremeter tests are numerically simulated by adopting the inverse analysis [19]. On the other hand, soil samples have been subjected to laboratory tests such as the identification tests that led the classification of the soil layers and the shear box tests that give a value of the internal friction angle varying from 18 to 21.5 degrees and the cohesion from 23 to $69 \mathrm{kPa}$.

The values of the internal friction angle computed numerically are the same as those measured in the laboratory. The calculated values of cohesion may differ from those determined from the shear box test; this is related to the disturbance of the soil samples tested in the laboratory. The comparison between the calculated elastic modulus $\mathrm{E}$ and the pressuremeter modulus $\mathrm{E}_{\mathrm{M}}$ recalls the empirical relation $\mathrm{E}_{\mathrm{M}} / \mathrm{E}=\alpha$ where $\alpha$ is between 0 and 1 .

Table 1 summarizes the mechanical parameters of soil layers as obtained from laboratory tests and numerical simulations.

\section{Slope Stability Study}

Slope stability problems are frequently encountered in the construction of roads, canals and dams as well as some natural slopes are or may become unstable due to the presence of water which weakens the soil characteristics or due to an excavation. The slip of a slope can be catastrophic and causes human losses in addition to considerable natural damages.

Once the mechanical characteristics of the slope's soil layers have been extracted from the numerical results of the pressuremeter and laboratory tests (Identification tests, shear box, simple compression test...), we proceed to model the slope by analyzing two profiles.

The studied slope with a maximum height of $150 \mathrm{~m}$ extends over a distance of $260 \mathrm{~m}$. Both profiles are illustrated in Fig. 3 and 4. They consist of several layers of soil whose parameters are summarized in Table 1.

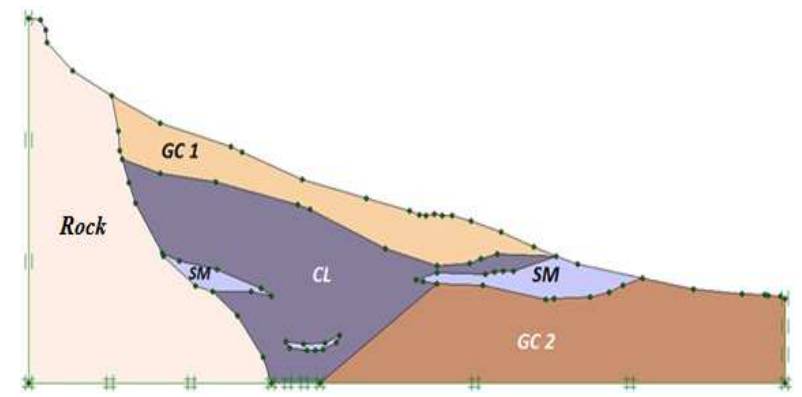

Figure 3. Geometry of profile $N^{o} 1$.

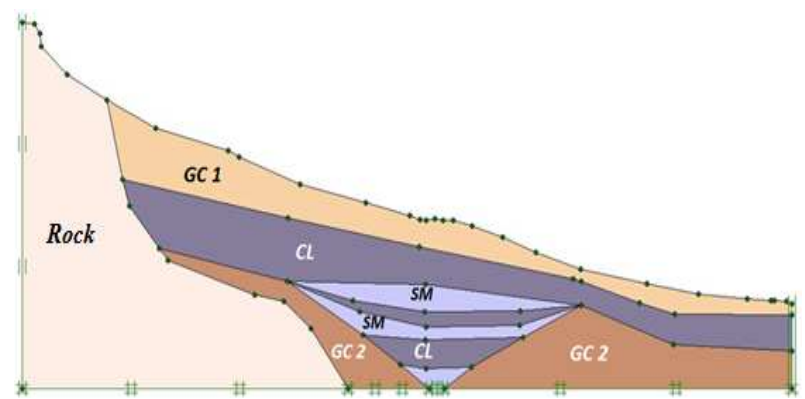

Figure 4. Geometry of profile $N^{o} 2$. 
Table 1. Properties of soil layers.

\begin{tabular}{|c|c|c|c|c|}
\hline Layer & Soil type & $\begin{array}{l}\text { Young modulus } \\
\mathrm{E}(\mathrm{kPa})\end{array}$ & $\begin{array}{l}\text { Cohesion } \\
\mathrm{C}(\mathrm{kPa}) \\
\end{array}$ & $\begin{array}{l}\text { Friction } \\
\text { angle } \varphi^{\circ}\end{array}$ \\
\hline Rock & Rock & 400000 & 800 & 20 \\
\hline GC1 & Clayey gravels & 20000 & 80 & 25 \\
\hline $\mathrm{CL}$ & $\begin{array}{l}\text { Sandy and clayey } \\
\text { marl }\end{array}$ & 20000 & 95 & 12 \\
\hline SM & Sandy with silt & 35000 & 350 & 30 \\
\hline $\mathrm{GC} 2$ & Clayey gravels & 30000 & 210 & 25 \\
\hline
\end{tabular}

Noting that these soil layers have a specific unsaturated weight $\gamma_{\text {unsat }}=18 \mathrm{kN} / \mathrm{m}^{3}$, a saturated weight $\gamma_{\mathrm{sat}}=19 \mathrm{kN} / \mathrm{m}^{3}$ and a Poisson's coefficient $v=0.3$.

\section{Stability Analysis}

The study of a slope is based on the calculation of a safety factor and the expectation of the sliding surface. A safety analysis in Plaxis can be executed by reducing the strength parameters of the soil. This process is called Phi-c reduction. In this approach, the strength parameters $\tan \varphi$ and $\mathbf{C}$ of the soil are successively reduced until the collapse of the slope occurs.

The total multiplier $\Sigma \mathrm{Msf}$ is defined as the ratio of the strength parameters entered as input values over the reduced ones. $\mathrm{EMsf}$ is set to 1 at the start of a calculation to set all material strengths to their unreduced values.

$$
\Sigma \mathrm{Msf}=\frac{\tan \varphi_{\text {input }}}{\tan \varphi_{\text {reduced }}}=\frac{C_{\text {input }}}{C_{\text {reduced }}}
$$

The strength parameters of soil are thereby reduced automatically step by step with an increment Msi equal to 0.1 until failure. The safety factor SF is given by the ratio of the available strength over the strength at failure. It is equal to the value of $\Sigma \mathrm{Msf}$ at failure.

\section{Results}

\subsection{Initial State}

First of all, the stability of the slope is studied in the case of homogeneity within each layer constituting the slope, the mechanical parameters are those derived from laboratory tests and numerical simulations of pressuremeter tests. The slope is considered in its natural state before any excavation. Under these conditions, the slope remained stable following the information held during the current and previous century. In a Phi-c reduction calculation, the field of the incremental displacements provides an indication of the failure mechanism. This surface seems circular for both profiles of the slope as shown in both Fig. 5 and 6. The safety factor obtained is equal to 2.24 for profile $\mathrm{N}^{\circ} 1$ and 2.13 for the second.

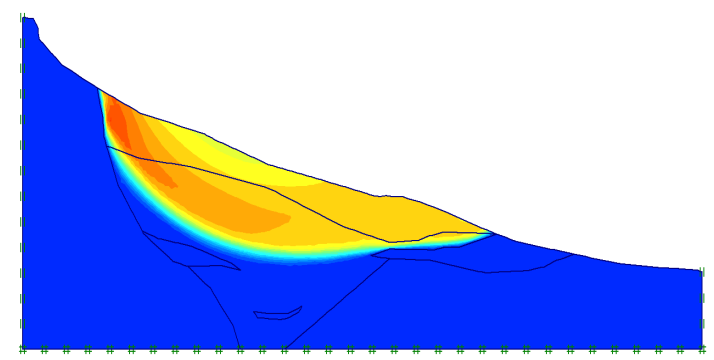

Figure 5. Failure surface of profile $N^{\circ} 1$, maximum displacement $u=1.3 \mathrm{~cm}$, $F S=2.24$.

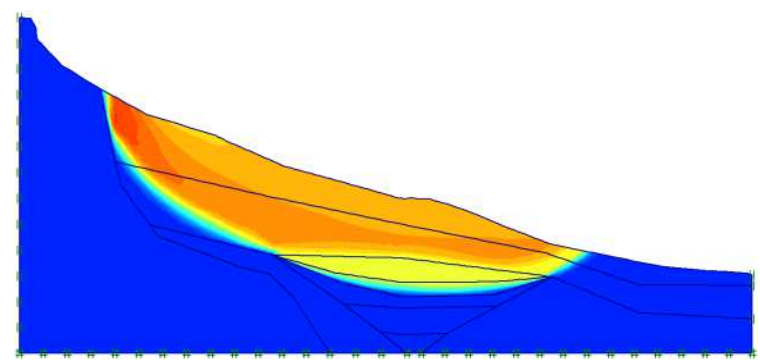

Figure 6. Failure surface of profile $N^{\circ} 2$, maximum displacement $u=2 \mathrm{~cm}$, $F S=2.13$.

\subsubsection{Activation of Seismic Load}

Following a seismic static load with an acceleration $\mathrm{a}=0.2 \mathrm{~g}$, we repeat the stability analysis. A safety factor greater than 1 is sufficient after the application of the seismic load. The "Phi-c reduction" method led to a safety factor of 1.26 for the profile 1 and 1.18 for profile 2 .

\subsubsection{Influence of an Excavation}

An excavation with a slope 3:2 reduces the safety factor of profile 1 to 2.07 (Fig. 7) with a maximum displacement of the slope of $1.6 \mathrm{~cm}$ while the coefficient is equal to 1.83 for the second profile (Fig. 8) and a maximum displacement of $0.97 \mathrm{~cm}$ and the slope remains stable.

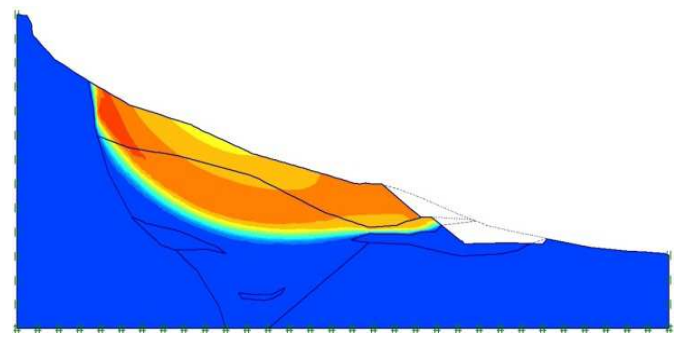

Figure 7. Failure surface of profile 1 after excavation 3:2, Displacement $u=1.6 \mathrm{~cm}, F S=2.07$

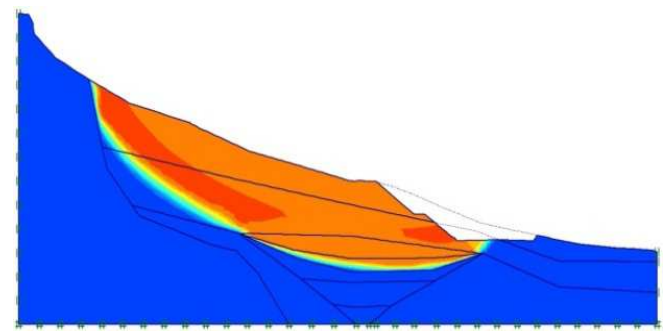

Figure 8. Failure surface of profile 2 after excavation $3: 2, u=0.97 \mathrm{~cm}$, $F S=1.83$. 
After the activation of the seismic load $a=0.2 g$, the safety factor becomes equal to 1.19 and 1.08 (Fig. 9) for profiles 1 and 2 respectively.

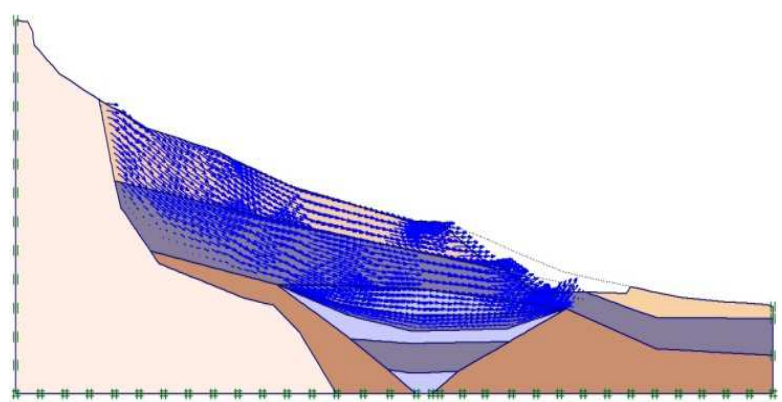

Figure 9. Failure surface of profile 2 after excavation 3:2, with seismic effect, $F S=1.08$.

\subsection{Sliding Causes}

Following the excavation executed during the dry season as shown in the figure above, the slope remained stable. During the next rainy season, the slope became unstable and collapsed. The water is the parameter which plays a critical role in the instability of slopes. In both profiles, we identify a clayey marl layer CL almost impermeable under a GC layer. Let us study the influence of water on the materials of the slope which caused the sliding.

The upper layer composed by a mixture of gravels, sands and clays contains 40 to $63 \%$ of gravels and 17 to $20 \%$ of sands. After saturation by water, if it loses from its mechanical characteristics, the internal friction angle's value will decrease for a few degrees; we examine the case when the cohesion loses half of its value.

The safety factor SF obtained in the static case decreases from 2.07 to 1.982 when the layer of clayey gravel loses half its cohesion ( $\mathrm{C}$ becomes $40 \mathrm{kPa}$ ) and $\varphi$ is reduced from $20^{\circ}$ to $18^{\circ}$. Considering the seismic effect, SF decreases from 1.18 to 1.158 . But the slope stays stable, and we must search another reason that caused the landslide.

The layer just below the GC layer is a layer of clayey marl CL almost impermeable. The accumulation of water flowing and remaining on the surface of this layer leads to a loss of mechanical properties of a part of the CL layer. The parameters will be reduced excessively and sometimes tend towards zero values.

According to Bjerrum [20], the internal friction angle for these cohesive soils may be reduced to its half value due to water's saturation. As for the cohesion, it can be highly decreased with the increase of the water content according to the law: $\mathrm{C}=\mathrm{k}(\mathrm{LL}-\mathrm{w})^{5}$.

The liquid limit values determined from laboratory tests vary from 25 to 36 with an average of 30 . Let us study the effect of the water content's increase of a thin thickness of 50 $\mathrm{cm}$ on the surface of CL layer. Following the formula proposed by Bjerrum, if the water content increases from 10 to $20 \%$, the cohesion $\mathrm{C}$ decreases from 95 to $2.9 \mathrm{kPa}$, and we suppose that $\varphi$ is then reduced to its half for this negligible value of $\mathrm{C}$.
The safety factor FS will be studied with the increase of water content. For $\mathrm{w}=12.5 \%, \mathrm{C}$ is reduced to it half $(48 \mathrm{kPa})$, for $\mathrm{w}=15 \%, \mathrm{C}$ is about $22 \mathrm{kPa}$ and for $\mathrm{w}=17.5 \%$, $\mathrm{C}$ is equal to $10 \mathrm{kPa}$. The elastic modulus determined in the saturated CL layer is about $1000 \mathrm{kPa}$. Mathé et al. [21] found a linear decrease of $\varphi$ with the increase of the water content for cohesive soils. From the graphs drawn by Ning Lu [22], we can approximate the following values of $\mathrm{E}$ which drops from $20000 \mathrm{kPa}$ to $1000 \mathrm{kPa}$ when $\mathrm{w}$ increases from 10 to $20 \%$.

Table 2. Corresponding values of $E$, $C$ and $\varphi$ according to the water content.

\begin{tabular}{llll}
\hline $\begin{array}{l}\text { Water content } \\
\mathbf{w}(\%)\end{array}$ & $\begin{array}{l}\text { Young modulus } \\
\mathbf{E}(\mathbf{k P a})\end{array}$ & $\begin{array}{l}\text { Cohesion } \\
\mathbf{C}(\mathbf{k P a})\end{array}$ & $\begin{array}{l}\text { Friction angle } \\
\boldsymbol{\varphi}^{\circ}\end{array}$ \\
\hline 12.5 & 15000 & 48 & 10.5 \\
15 & 10000 & 22 & 9 \\
17 & 4000 & 10 & 8 \\
20 & 1000 & 2.9 & 6 \\
\hline
\end{tabular}

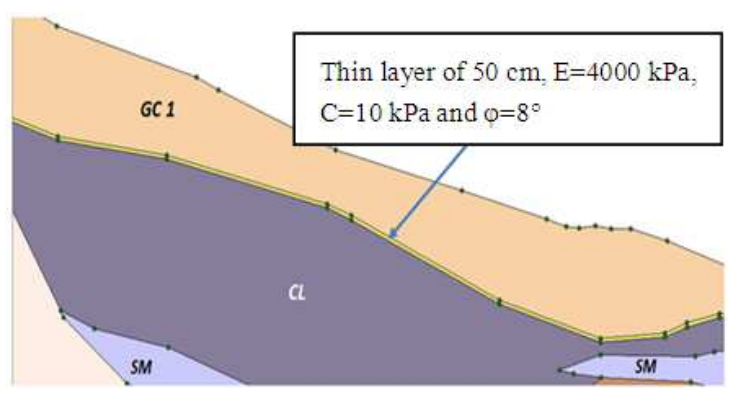

Figure 10. Thin layer characteristics.

The safety factor coefficient of the unexcavated slope varies with the water content. This variation is plotted in Fig. 11; in case of the thin layer development on the surface of CL layer.

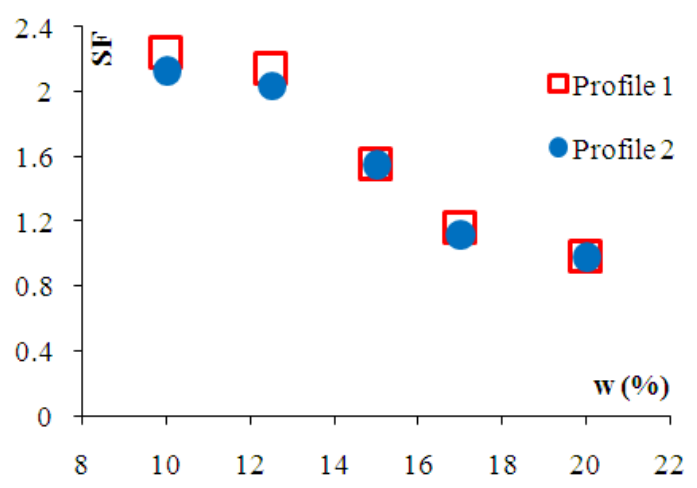

Figure 11. Variation of safety factor SF in function of the water content $w$ (unexcavated slope with a thin layer).

SF decreases when the moisture content increases and the sliding surface turns from circular to plane. The failure occurs when the water content of the thin layer reaches $20 \%$. In this case, the cohesion of this $50 \mathrm{~cm}$ layer is negligible; the friction angle is about 6 degrees and the elastic modulus E equals to $1 \mathrm{MPa}$. As the slope has always remained stable 
when left intact in its natural state, therefore, these mechanical parameters are never reached. However, when $\mathrm{w}$ is equal to $17 \%, \mathrm{C}$ is about $10 \mathrm{kPa}, \varphi$ is approximately $8^{\circ}$ and $\mathrm{E}$ is $4000 \mathrm{kPa}$, the safety factor is 1.15 for the first profile and 1.12 for the second with a plane failure surface. This is the case of a questionable safety in which the excavation works executed must be analyzed.

The failure surface of the profile 1 turns towards to a plane slide when the water content of the thin layer is about $12.5 \%\left(\mathrm{E}=15000 \mathrm{kPa}, \mathrm{C}=48 \mathrm{kPa}\right.$ and $\left.\varphi=10.5^{\circ}\right)$ (Fig. 12), becomes completely plane when $\mathrm{w}$ reaches $15 \%(\mathrm{E}=10000$ $\mathrm{kPa}, \mathrm{C}=22 \mathrm{kPa}$ and $\varphi=9^{\circ}$ ) (Fig. 13) and the slope is close to instability when w attains $17 \%(\mathrm{E}=4000 \mathrm{kPa}, \mathrm{C}=10 \mathrm{kPa}$ and $\varphi=8^{\circ}$ ) (Fig. 14)

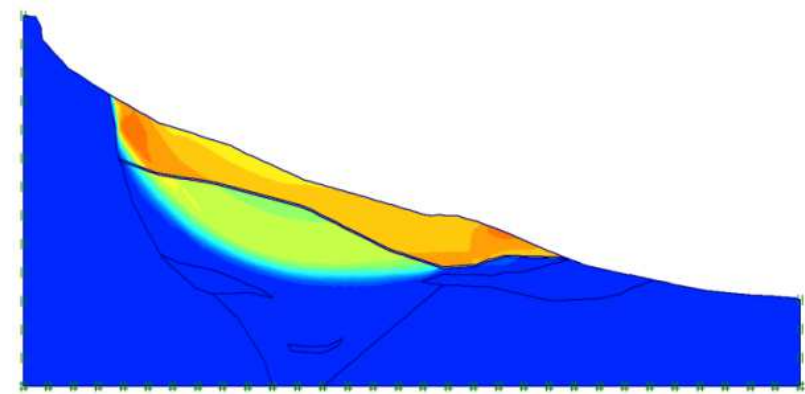

Figure 12. $E=15000 \mathrm{kPa}, C=48 \mathrm{kPa}$ and $\varphi=10.5^{\circ}, F S=2.14$ and the failure surface turns to be plane.

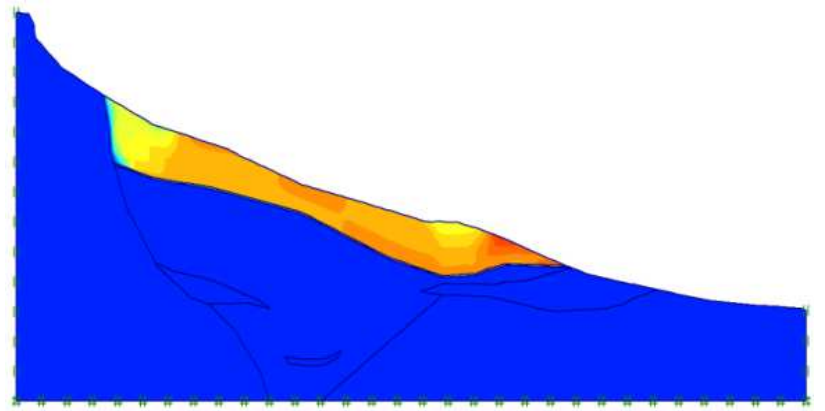

Figure 13. $E=10000 \mathrm{kPa}, \mathrm{C}=22 \mathrm{kPa}$ and $\varphi=9^{\circ}, F S=1.55$ and the failure surface is plane.

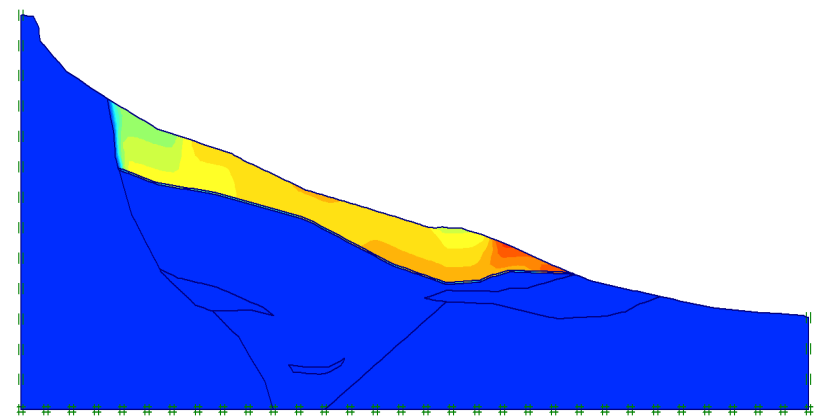

Figure 14. Failure surface for profile $N^{\circ} 1$ with a thin layer, plane slide, $E=4000 \mathrm{kPa}, C=10 \mathrm{kPa}$ and $\varphi=8^{\circ}, F S=1.15$.

For profile 2, it moves quickly towards the plane slip when the water content of the thin layer increases (Fig. 15).

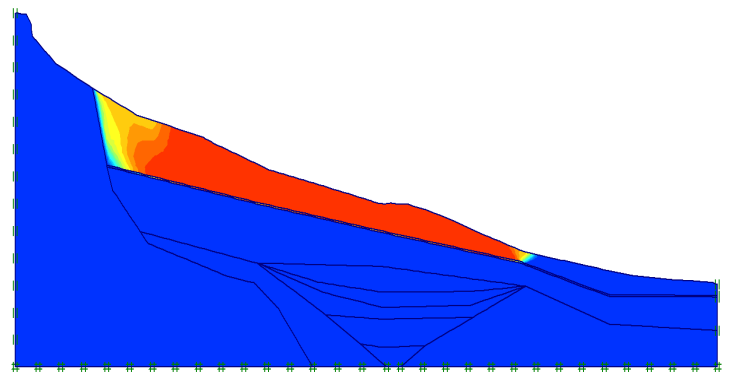

Figure 15. Sliding surface for profile $N^{\circ} 2$ with a thin layer, plane slide, $E=4000 \mathrm{kPa}, C=10 \mathrm{kPa}$ and $\varphi=8^{\circ}, F S=1.12$.

\subsubsection{Excavation Influence}

The slope excavated in real case with a 3:2 slope that caused the landslide is modeled with Plaxis. The study of the slope with a thin surface of the CL layer where its water content increases excessively shows that the sliding surface is plane as shown in both Fig. 17 and 18 for both profiles. Consequently, when $\mathrm{w}$ reaches $17 \%(\mathrm{E}=4000 \mathrm{kPa}$, $\mathrm{C}=10 \mathrm{kPa}$ and $\varphi=8^{\circ}$ ), the safety factor is 0.96 for the first profile and 0.95 for the second. The variation of the safety factor according to the increase of the water content is plotted in Fig. 16.

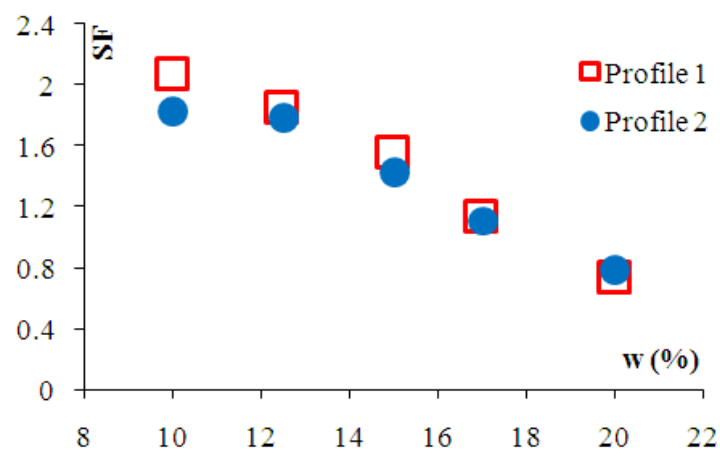

Figure 16. Variation of safety factor SF in function of the water content $w$ (excavated slope with a thin layer).

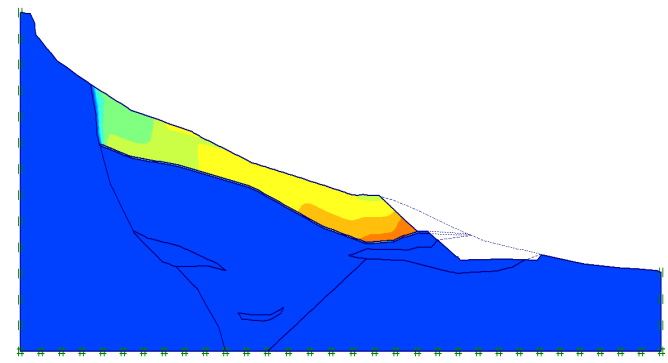

Figure 17. Sliding surface for profile $N^{\circ} 1$ after excavation 3:2, $F S=0.96$.

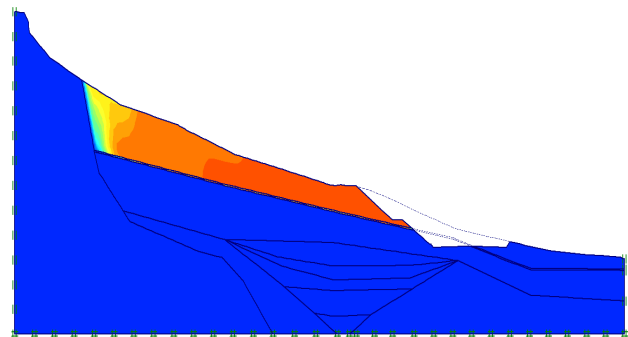

Figure 18. Failure surface for profile $N^{\circ} 2$ after excavation 3:2, FS $=0.95$ 
A thin layer characterized by very low mechanical parameters due to its water saturation causes a plane sliding surface as shown above.

Let us consider the case where the clayey marl layer CL remains homogeneous, assuming that the increase in water content is homogeneously throughout the CL layer without the development of a thin layer. By adopting the variation of mechanical parameters of the CL layer with the water content described above, we plot the variation of the safety factor with the water content (Fig. 19) where the failure mode observed is circular. (Fig. 20 and 21)

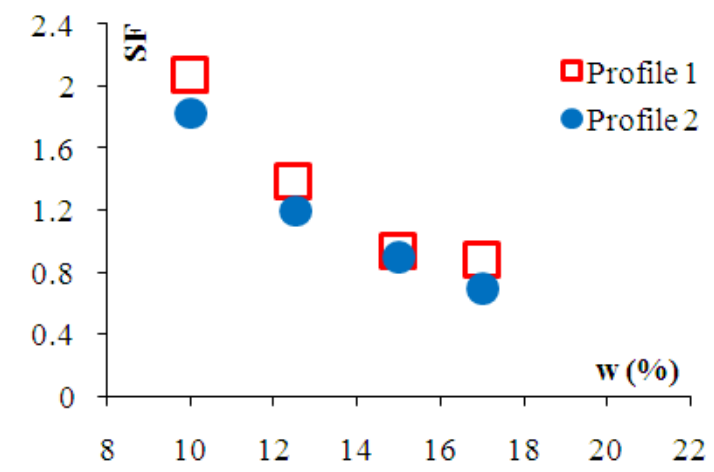

Figure 19. Variation of safety factor SF in function of the water content $w$ (excavated slope with a homogeneous CL layer)

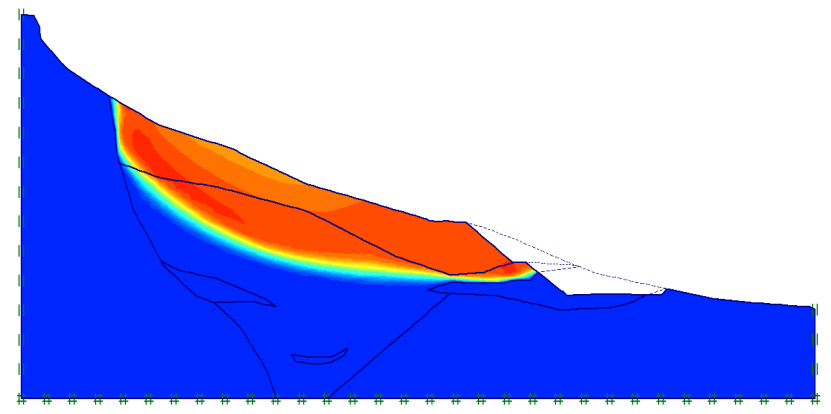

Figure 20. Failure surface for profile $N^{\circ} 1$ after excavation 3:2, $F S=0.93$, circular surface, homogeneous CL layer with these parameters: $E=10000$ $k P a, C=22 k P a$ and $\varphi=9^{\circ}$.

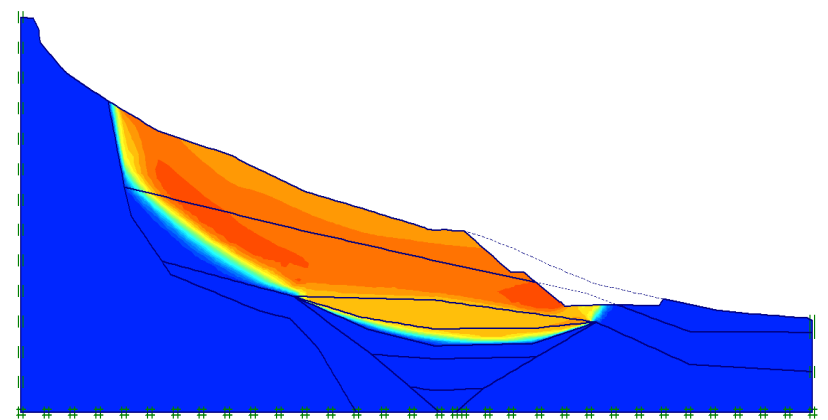

Figure 21. Sliding surface for profile $N^{\circ} 2$ after excavation 3:2, $F S=0.90$, circular surface, homogeneous CL layer with these parameters: $E=10000$ $k P a, C=22 \mathrm{kPa}$ and $\varphi=9^{\circ}$.

The possibility of forming a thin layer of low mechanical characteristics depends on the degree of impermeability of the CL layer. The failure mode depends on the existence of this layer which too probable to be developed due to the high percentage of fine materials ( 70 to $88 \%$ ) of the CL layer. We note also that its liquid limit is between 25 and 38 and the plasticity index varies from 11 to 21 . However, a permeability test is necessary to confirm the development of that weak thin layer.

\subsection{Remedies}

In order to stabilize the slope, several remedies have been studied. We assumed that a thin layer characterized by a high water content $\mathrm{w}=17 \%$ was developed at the surface of the CL layer, causing the plane slip of the slope. Some confrontations methods are summarized as follows:

\subsubsection{Piles}

The stabilization of the slope by several rows of piles spaced of $3.6 \mathrm{~m}$ with a diameter of $1.2 \mathrm{~m}$ and a length of $36 \mathrm{~m}$ led to a safety factor of 1.7 for the first profile (1 row) and 1.5 for the second (2 rows). Once the seismic loading is applied, three rows of piles will be required for each profile so that the factor is greater than 1 .

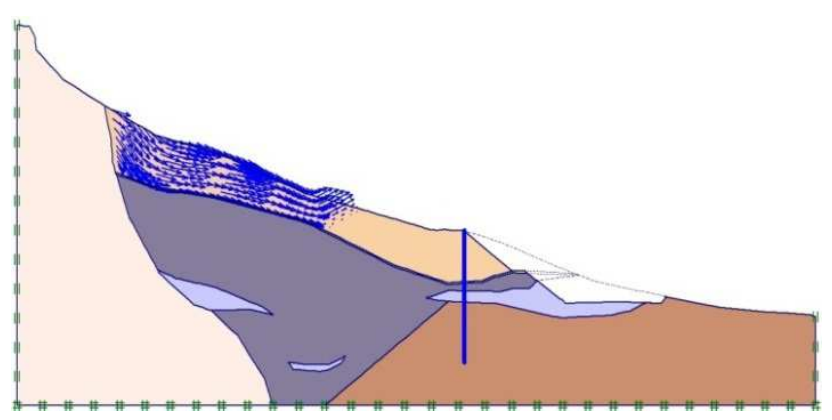

Figure 22. Failure surface of profile $N^{o} 1$ after piles activation, $F S=1.7$.

\subsubsection{Nails}

One series of steel nails spaced of $2 \mathrm{~m}$, with a diameter of $15 \mathrm{~cm}$ and a length of $20 \mathrm{~m}$ is sufficient to get a safety factor equal to 1.5 for the profile 1 , while three rows are necessary to obtain the same coefficient for profile 2 . When seismic effect is taken into account, the first profile needs 5 rows to be stable while the second stills unstable even by increasing the number of nails and by varying their positions.

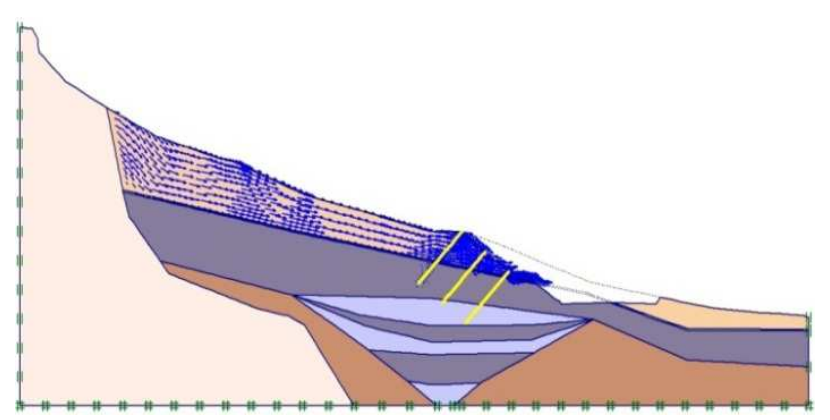

Figure 23. Failure surface of profile $N^{o} 2$ after nails activation, $F S=1.5$.

\subsubsection{Barrettes}

The barrettes disposed are in T-shaped spaced of $3.6 \mathrm{~m}$ with a normal stiffness $E A=2.8 \times 10^{7} \mathrm{kN} / \mathrm{m}$ and a flexural rigidity $\mathbf{E I}=4.3 \times 10^{7} \mathrm{kN} / \mathrm{m}^{2} / \mathrm{m}$. The stability 
calculation showed that a row of barrettes and another of piles are required to achieve for the profile 1 a safety factor equal to 2.07 which decreases to 1.13 after the seismic loading. For profile 2, the stability study revealed the need for one series of barrettes and two of piles, so it is more economical to adopt the solution of the 3 series of piles.

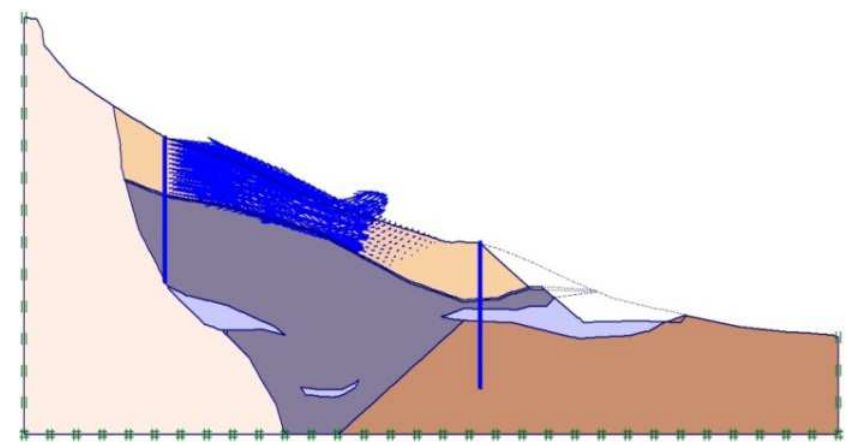

Figure 24. Sliding surface of profile 1 with barrettes, piles and seismic loads, $F S=1.13$.

\subsubsection{Drains}

It is remarkable that the presence of the water in the slopes contributes to adverse slide phenomena. In this regard, we studied the influence of vertical drains on the stability of slopes. They are modeled by drain constituting from filter materials allowing the water to be discharged through a longitudinally natural watercourse. These drains prevent also the accumulation of water at the CL layer surface which maintains consequently its initial mechanical properties. For partial drainage, one series of piles or nails is sufficient to be on the safe side even after applying seismic loads. It is also noted that the slope's sliding surface returns circular.

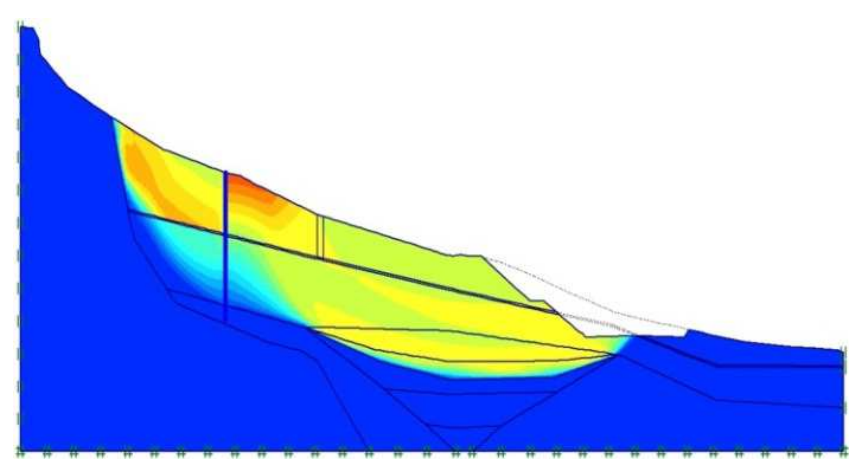

Figure 25. Partial drainage, circular sliding surface.

When the slope is fully drained, the calculation showed a safe state even without the disposition of any kind of reinforcement.

\subsubsection{Slope Softening}

The slopes softening methods increase the safety factor values to become between 1 and 1.5. The arrangement of piles or nails has identified the most stable model by obtaining factor higher than 1.5 and we notice a decrease in their number after earthworks and drain process.

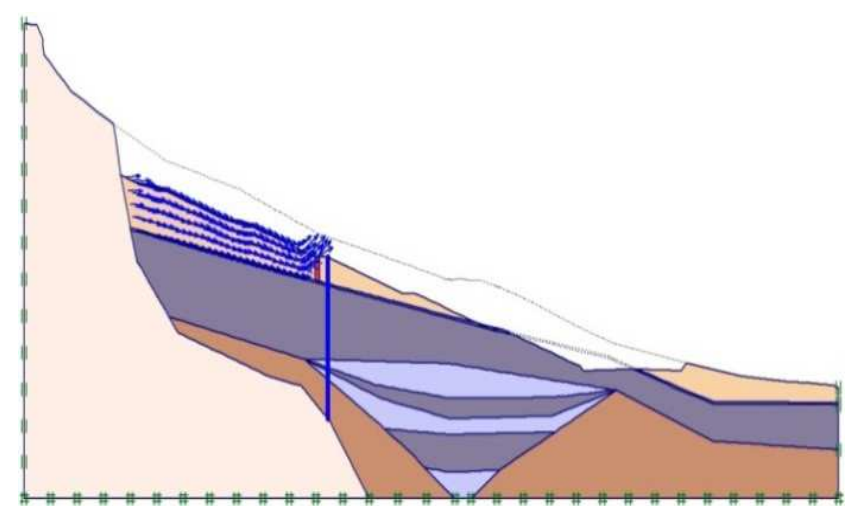

Figure 26. Sliding surface of profile 2 after slope softening, partial drainage and seismic loads, $F S=1.03$.

\section{Conclusion}

A landslide occurs in a slope near Dahr Elbaidar in Lebanon during roads excavation works. The numerical simulations of in-situ pressuremeter tests based on laboratory results have allowed the characterization of soil layers. The decrease of the mechanical parameters of the soil due to the increase in water content is the main cause of the slide. The homogeneity within the layers leads to a circular failure mode which turns to plane in case of the presence of a thin layer of low mechanical characteristics. The drainage is an effective way to stabilize the slope. When the slope is fully drained, the stability is ensured even without any strengthening methods. The partial drain needs to be accompanied by another means of reinforcement such as piles or nails. The distribution of the piles or nails along the slope is more efficient to ensure stability that the use of a high inertia member disposed in one place of this slope.

\section{Acknowledgment}

We express our acknowledgement to CNRS - Lebanon for his financial support of our research.

\section{References}

[1] W. Fellenius, Erdstatische Berechnungen Mit Reibung Und Kohaesion. Berlin, Ernst, 1927.

[2] A.W. Bishop, The Use of the Slip Circle in the Stability Analysis of Slopes, Geotechnique, 5 (1), 1955, pp.7-17.

[3] J.L. Durville and G. Sève, Stabilité des Pentes. Glissements en Terrain Meuble, Techniques de l'ingénieur, traité construction, chap. C 254, 1996, 16 p.

[4] R. M. Faure, L'évolution des Méthodes de Calcul de Stabilité des Pentes Partie 1: Méthodes à la Rupture, Revue Française de Géotechnique, No. 92, 2001, p. 3-16.

[5] X.P. Zhou and H. Cheng, Analysis of Stability of Three-Dimensional Slopes Using the Rigorous Limit Equilibrium Method, Engineering Geology 160, 2013, pp. 21-33. 
[6] W. Alkasawneh, A.I.H. Malkawi, J. Nusairat and N. Albataineh, A Comparative Study of Various Commercially Available Programs in Slope Stability Analysis, Computers and Geotechnics 35, 2008, pp. 428-435.

[7] D.V. Griffoths and P.A. Lane, Slope Stability Analysis by Finite Elements, Géotechnique 49, No. 3, 1999, pp. 387-403.

[8] Y. M. Cheng, I. Lansivaara and W. B. Wei, Two-Dimensional Slope Stability Analysis by Limit Equilibrium and Strength Reduction Methods, Computers and Geotechnics 34, 2007, pp. 137-150.

[9] M. Huang and C. Q. Jia, Strength Reduction FEM in Stability Analysis of Soil Slopes Subjected to Transient Unsaturated Seepage, Computers and Geotechnics 36, 2009, pp. 93-101.

[10] Y. S. Song, W. P. Hong and K. S. Woo, Behavior and Analysis of Stabilizing Piles Installed in a Cut Slope during Rainfall, Engineering Geology, 129-130, 2012, pp.56-67.

[11] W. B. Wei and Y. M. Cheng, Strength Reduction Analysis for Slope Reinforced with one Row of Piles, Computers and Geotechnics 36, 2009, pp. 1176-1185.

[12] R. Kourkoulis, F. Gelagoti, I. Anastasopoulos ans G. Gazetas, Slope Stabilizing Piles and Pile-Groups: Parametric Study and Design Insights, Journal of Geotechnical and Geoenvironmental Engineering, ASCE, 137(7), July 2011, pp.663-677

[13] S. He, C. Ouyang and Y. Luo, Seismic Stability Analysis of Soil Nail Reinforced Slope using Kinematic Approach of Limit Analysis, Environmental Earth Sciences 66(1), 2012, pp. 319-326.
[14] C. Fan and J. Luo, Numerical Study on the Optimum Layout of Soil-Nailed Slope, Computers and Geotechnics, 35, 2008, p. 585-599.

[15] G. Carter, La stabilisation des Pentes Instables par Clouage. Bulletin liaison des Ponts et Chaussées, 141, 1986, p. 45-56.

[16] W. B. Wei and Y. M. Cheng, Soil Nailed Slope by Strength Reduction and Limit Equilibrium Methods, Computers and Geotechnics 37, 2010, pp. 602-618.

[17] P. Valli, Numerical Study to Stabilize Landslides by Trench Drains, Computers and Geotechnics, 27, 2000, p. 63-77.

[18] F. Cai, K. Ugai, A. Wakai and Q. Li, Effects of Horizontal Drains on Slope Stability Under Rainfall by Three-Dimensional Finite Element Analysis, Computers and Geotechnics, 23, 1998, pp.255-275.

[19] A. Fawaz, E. Farah and F. HageChehade, A Numerical Analysis Determining the Shear Resistance of Soil from the Pressuremeter Test and Compared to Analytical Studies, Journal of Civil Engineering and Science JCES, vol 2, Iss 3, Sep 2013, pp.202-211.

[20] L. Bjerrum, Fundamental Consideration on the Shear Strength of Soil. Geotechnique, Vol. 2, No. 3, 1951, pp. 209-218.

[21] L. Mathé, G. Pillinger and P. Kiss, Effects of Varying Moisture Content and Settlement on Internal Friction, Load Capacity and Cohesion in Loam Soil. FISITA 2010, SC-O-17.

[22] N. Lu, A Power Law for Elastic Moduli of Unsaturated Soil. Springer-verlag, Berlin Heidelberg, 2013, pp. 271-275. 